\title{
Stent Survival and Stent-Adjacent Stenosis Rates following Venous Sinus Stenting for Idiopathic Intracranial Hypertension: A Systematic Review and Meta-Analysis
}

\author{
Hamidreza Saber ${ }^{a}$ Whitfield Lewis ${ }^{a}$ Mahsa Sadeghi ${ }^{a}$ Gary Rajah ${ }^{b}$ \\ Sandra Narayanan ${ }^{a, b}$ \\ aDepartment of Neurology, Wayne State University School of Medicine, Detroit, MI, USA; \\ ${ }^{b}$ Department of Neurosurgery, Wayne State University School of Medicine, Detroit, MI, USA
}

\section{Keywords}

Idiopathic intracranial hypertension · Venous sinus stenting · Systematic review · Metaanalysis

\begin{abstract}
Background: Idiopathic intracranial hypertension (IIH) is characterized by an elevated intracranial pressure without any identifiable causative factor such as an intracranial mass. Dural venous sinus stenosis (DVSS) has been suggested to be associated with IIH. Objective: We performed an updated systematic review and meta-analysis to determine clinical outcomes as well as stent survival and stent-adjacent stenosis rates in patients undergoing DVSS for the management of medically refractory $\mathrm{IIH}$. Methods: We searched PubMed, Embase, and Cochrane databases to identify prospective or retrospective cohorts or case series of patients with IIH treated with DVSS between 2000 and 2017. Results: A total of 473 patients were included from 24 studies. Headache was present in 429 (91.8\%) patients and resolved or improved in 319/413 (77.2\%) after the procedure. Headache, papilledema, visual acuity, and tinnitus improved in 256/330 (77.6\%), 247/288 (85.8\%), 121/172 (70.3\%), and 93/110 (84.5\%) patients following DVSS at the final follow-up (mean of 18.3 months). In a meta-analysis of 395 patients with available follow-up data on stenting outcome (mean of 18.9 months), the stent survival and stent-adjacent stenosis rates were $84 \%$ (95\% confidence interval [Cl] 79$87 \%$ ) and $14 \%$ (95\% Cl 11-18\%), respectively. The rate of major neurological complications was less than $2 \%$. Conclusion: Stent-adjacent stenosis is an important complication following venous stenting in patients with DVSS and $\mathrm{IH}$. Further studies are needed to identify determinants of stent-adjacent stenosis and stent nonsurvival.




\section{Introduction}

Refractory idiopathic intracranial hypertension (IIH) is a syndrome of increased intracranial pressure (ICP) without any mass lesion in the brain, mainly affecting obese women of childbearing age, that is unresponsive to medical therapy [1]. Common associated clinical findings include headache, pulse-synchronous tinnitus, visual field disturbances, papilledema, and possible visual loss because of chronic papilledema.

Current surgical treatments of refractory IIH including cerebrospinal fluid (CSF) diversion (shunting) and optic nerve fenestration are associated with high rates of complications (7.6 and $32.3 \%, 1.5$ and $16.4 \%$ major and minor complications, respectively) and recurrence of IIH-related symptoms [2]. Furthermore, it is thought that in cases where dural venous sinus stenosis (DVSS) is present both shunting and optic nerve sheath fenestration are providing only a temporary relief to the physiological problem at hand. More recently, there has been a growing body of evidence on the role of DVSS in the etiology of IIH [2]. Whether the DVSS is the cause or a consequence of increased ICP is still debated [3]. However, venous sinus stenting has been proposed as a surgical treatment associated with good clinical outcomes in several retrospective cohorts and case series.

The long-term rates of stent survival as well as determinants of stent failure in patients who undergo venous sinus stenting are not well established. Prior reports have suggested varying rates of stent-adjacent (proximal or distal) stenosis as a main reason for treatment failure after DVSS [4-22] as well as different clinical outcomes [4-26]. In this analysis, we aimed to provide an updated systematic review of DVSS outcomes and to determine overall stent survival and stent-adjacent stenosis rates based on available evidence.

\section{Methods}

Literature Search

This review was conducted in accordance with PRISMA (Preferred Reporting Items for Systematic Reviews and Meta-Analyses) guidelines. The database search including PubMed, Embase, and Cochrane was performed by two of the authors. The search terms were ("idiopathic intracranial hypertension" OR "pseudotumor cerebri") AND ("venous sinus stenting"). After eliminating duplicates and irrelevant articles, fulltext reports were reviewed. Subsequently, we performed a hand search of all included studies until no further relevant studies were identified. Disagreements between the two reviewers were resolved by the third reviewer. The electronic search was last updated on December 20, 2017. Studies were included if there were more than 3 patients treated with venous sinus stenting and main clinical outcomes reported for patients treated with venous stenting.

\section{Data Extraction and Outcomes}

Demographic and baseline information, treatment, and clinical and safety outcomes were extracted from eligible studies.

Clinical outcomes included improvement in headache, tinnitus, visual changes, and papilledema. The main stent-related outcomes were stent nonrevision rates (stent survival) and stent-adjacent stenosis. Stent survival was defined as patients not undergoing any type of procedural treatment following the initial stenting as a result of persistency of symptoms, in-stent stenosis, stent-adjacent stenosis, or contralateral venous sinus stenosis. Major safety outcomes included ischemic or hemorrhagic complications.

Statistical Analysis

Clinical outcome improvement rates for DVSS were calculated. Stent-related outcomes were assessed by meta-analysis using R for statistical programming. Fixed- or random-effects models were used for metaanalysis as appropriate. 
Saber et al.: Stent Survival and Stent-Adjacent Stenosis Rates following Venous Sinus Stenting for IIH

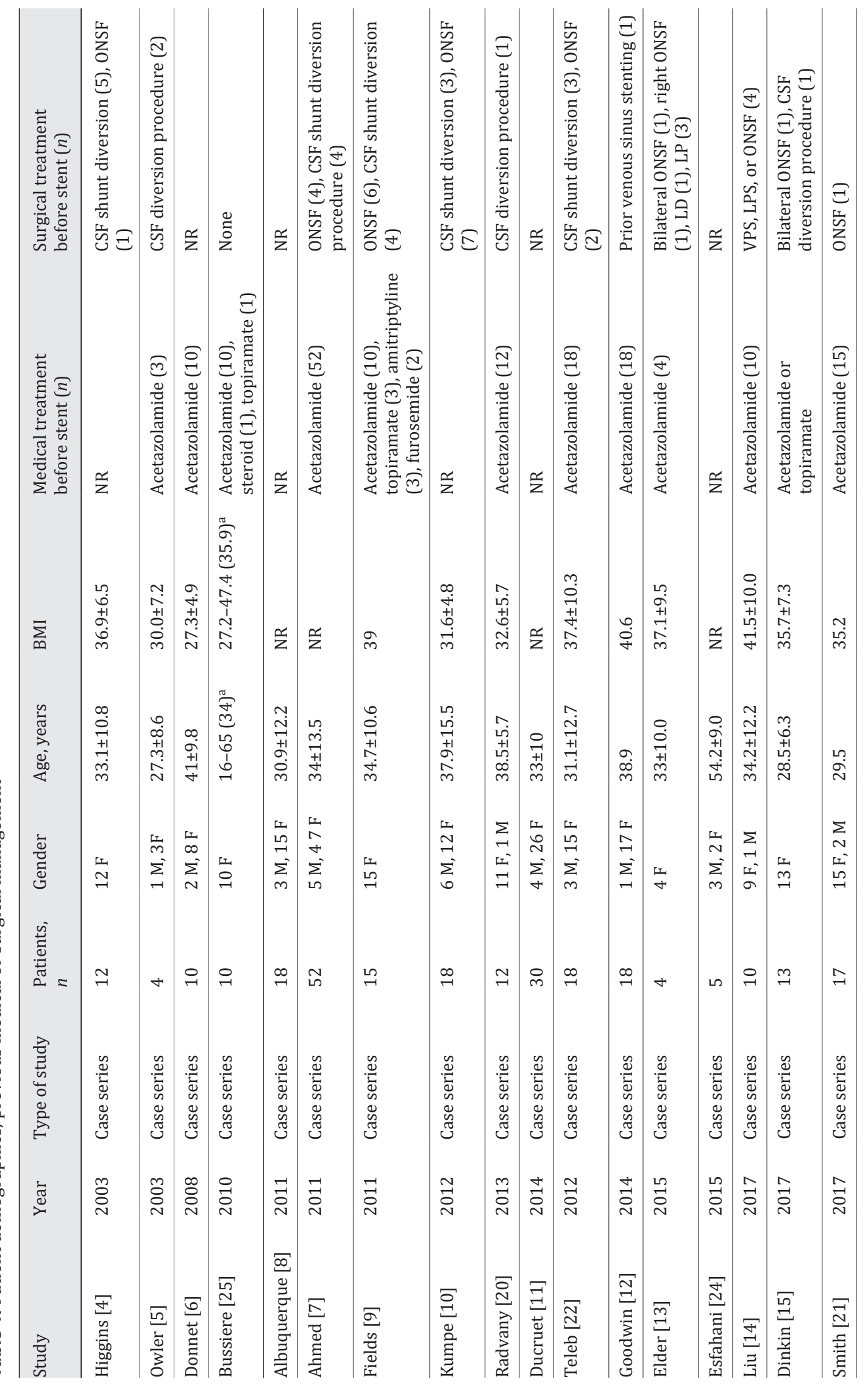


Saber et al:: Stent Survival and Stent-Adjacent Stenosis Rates following Venous Sinus Stenting for IIH

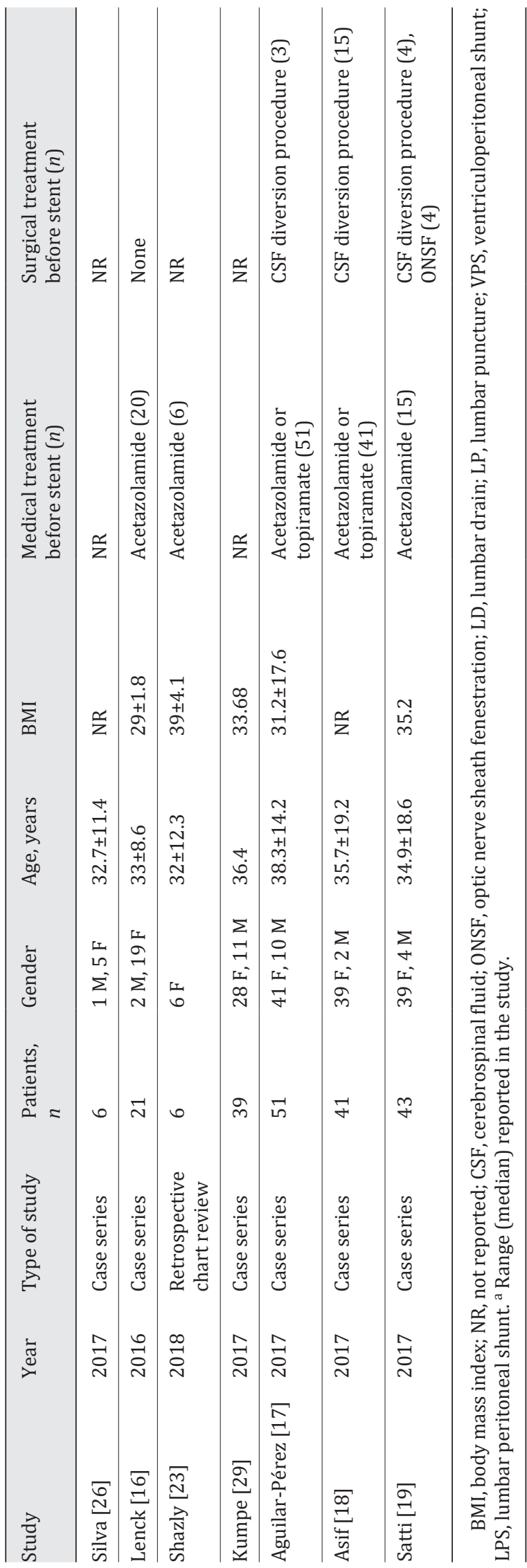




\section{Results}

We identified 473 patients from 24 studies for inclusion in our systematic review. The study followed the PRISMA guidelines for systematic reviews. Our results demonstrated that $86 \%$ of patients were females and the average BMI and lumbar puncture opening pressure were 34.8 and 38.6, respectively (Table 1 ). Headache, papilledema, visual acuity, and tinnitus were present in $91.8,86.8,72.7$, and $48.9 \%$ of patients, respectively. Overall, 368 patients were followed clinically on a long-term basis (mean follow-up 18.3 months). Symptomatic improvement in patients with available long-term follow-up data was $77.6 \%$ for headache (256/330), 85.8\% for papilledema (247/288), 70.3\% for visual acuity (121/172), and $84.5 \%$ for tinnitus (93/110). A total of 395 patients were radiographically followed using computerized tomography venography, magnetic resonance venogram, or digital subtraction angiogram (mean follow-up 18.9 months). Also, a total of 79 patients (4 studies) were followed up with cerebral angiograms for long-term assessment of the pressure gradient. The initial pressure gradient before stenting was $20.0 \mathrm{~mm} \mathrm{Hg}$, and the average final pressure gradient after stenting was $3.2 \mathrm{~mm} \mathrm{Hg}$ (mean follow-up 7.9 months) (Table 2). Major neurological complications were noted to be less than $2 \%$. In a meta-analysis of 395 patients with followup data on stenting outcome, stent survival was 84\% (95\% confidence interval [CI] 79-87\%) at a mean of 20 months of follow-up (Fig. 1). Overall, 14\% (95\% CI 11-18\%) of patients experienced stent-adjacent stenosis over the same time period (Fig. 2).

\section{Discussion}

The annual incidence of IIH is around 1 per 100,000 in the general population in the US, and as high as 20 per 100,000 in overweight women between the ages of 20 and 44 years. Interestingly, DVSS has been commonly reported in 50-90\% of patients with $\mathrm{IIH}$, most of whom are responsive to medical therapy and weight loss [27]. This rate may be up to $100 \%$ in patients with refractory IIH. The diagnosis is made according to the modified Dandy Criteria and can be due to different underlying pathophysiological mechanisms including DVSS. Once medical therapy has failed, surgical optic nerve sheath fenestration, shunting, and venous stenting remain options.

The pathogenesis of IIH is multifactorial. Drugs and high estrogen levels are known causes of IIH, the pathogenesis being an increased CSF production. On the other hand, an impairment in CSF absorption can also be the inciting factor leading to IIH. The relationship between DVSS and IIH has been the subject of inquiry. There are two types of stenosis associated with IIH. The first is a long tapering stenosis with normal appearance of arachnoid granulations on the vascular imaging (e.g., magnetic resonance venogram). The second type is a more focal stenosis as a result of hypertrophy of arachnoid granulations, focal fibrosis, septations, or fatty deposits. In the study by Ahmed et al. [7], 5 out of the 6 patients that underwent re-stenting had a long tapering type of venous sinus stenosis. Stent failures in these patients were all accompanied by stent-adjacent stenosis. A positive feedback mechanism could explain how increased ICP will ultimately result in DVSS whereby worsening ICP. This results in worsening extrinsic compression and worsening of the venous sinuses which in turn could impede CSF outflow resulting in further increase in ICP. Venous sinus stenting in these patients may reduce this positive feedback loop and could theoretically relieve symptoms of IIH. However, further compression of venous sinuses outside the area of stenting may continue to be present as the inciting factor leading to IIH has not been corrected. In contrast, relieving the focal stenosis seen in the intrinsic type of DVSS would likely not result in stent-adjacent stenosis as venous sinus stenting relieves the primary cause of IIH in these patients. 
Interventional

Neurology
Intervent Neurol 2018;7:490-500

DOI: $10.1159 / 000490578$

2018 S. Karger AG, Base

Saber et al.: Stent Survival and Stent-Adjacent Stenosis Rates following Venous Sinus Stenting for IIH

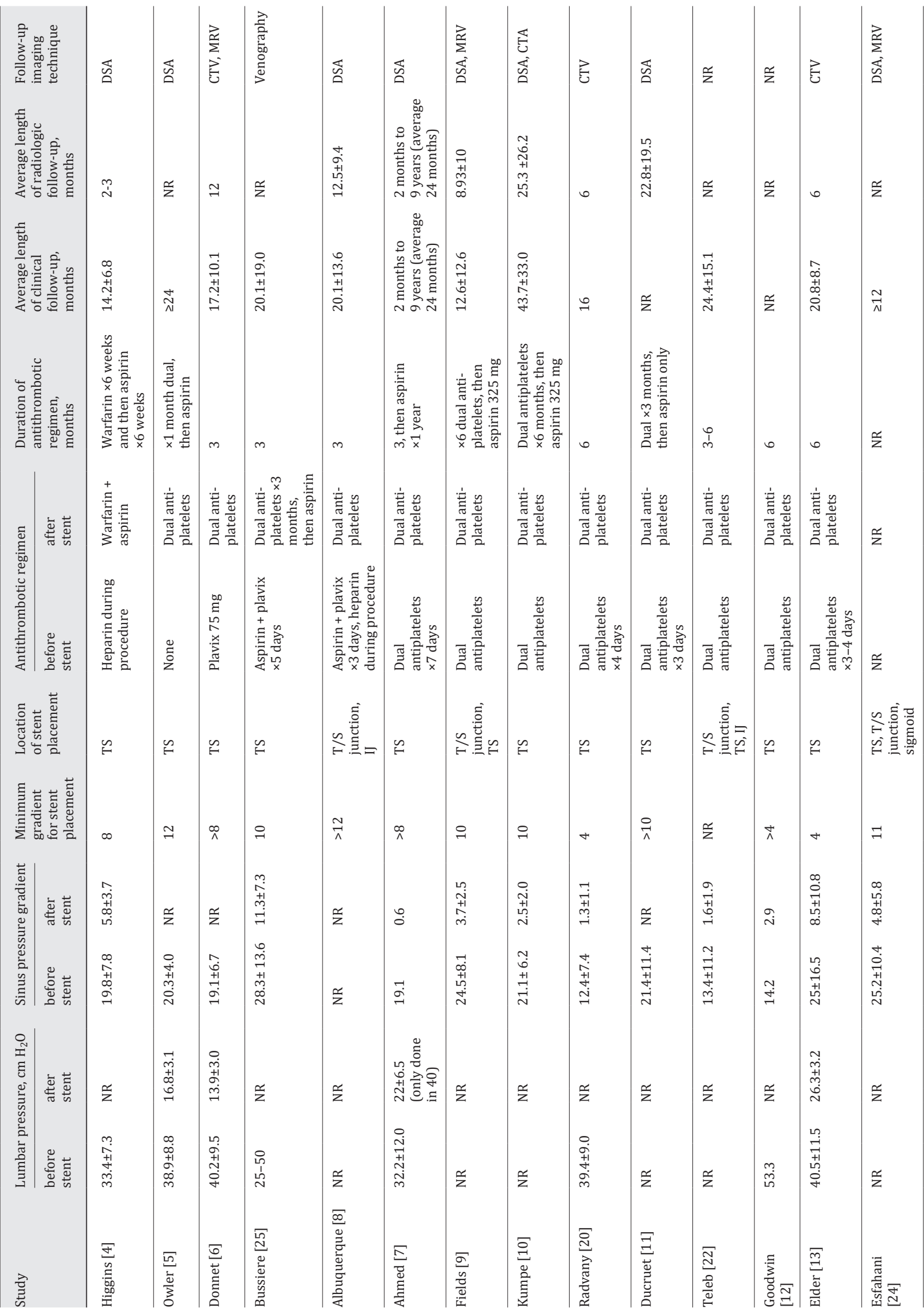


Saber et al.: Stent Survival and Stent-Adjacent Stenosis Rates following Venous Sinus Stenting for IIH

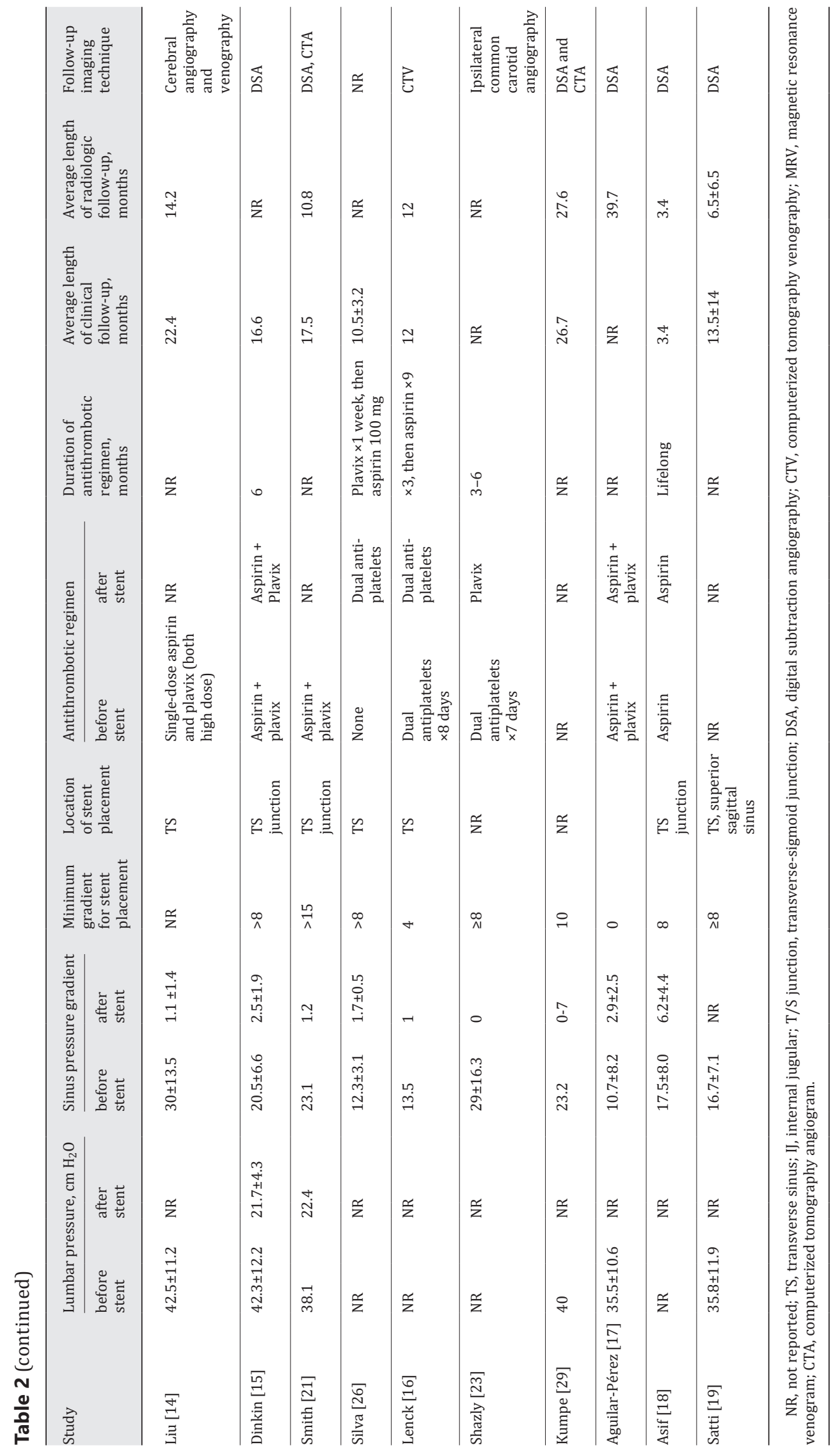


Saber et al.: Stent Survival and Stent-Adjacent Stenosis Rates following Venous Sinus Stenting for IIH

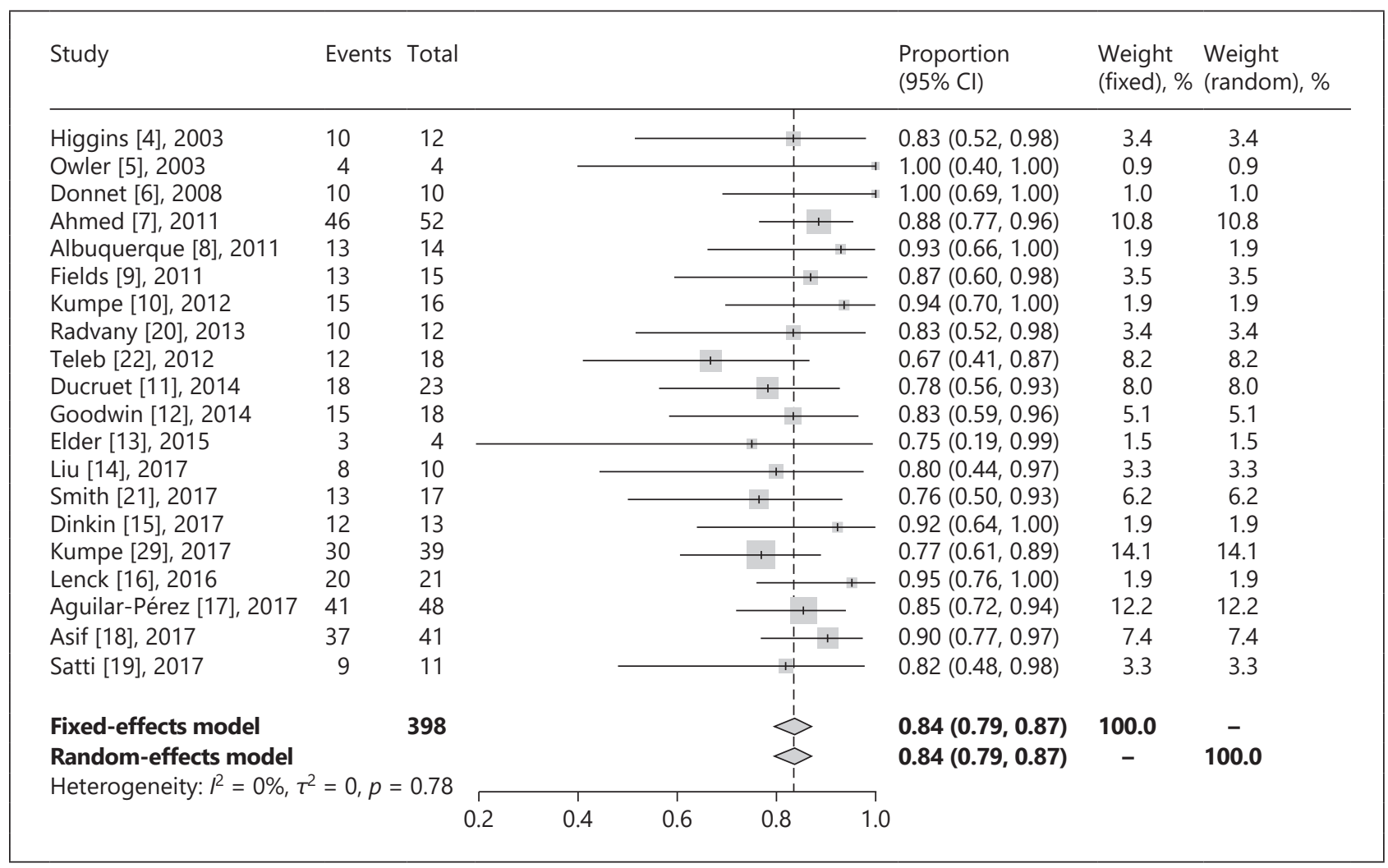

Fig. 1. Venous sinus stent survival rate.

We observed high rates for improvement of signs and symptoms associated with refractory IIH following venous stenting similar to another large meta-analysis [2]. Tinnitus and papilledema were symptoms associated with the highest likelihood of response to venous stenting. Reductions in pressure gradients were significantly correlated with resolution of symptoms. Venous stenting was associated with a significant reduction in pressure gradient across the site of stenosis and CSF pressure before and after the procedure. Overall, stent failure and stent-adjacent stenosis rates were low after dural venous sinus stenting.

Manometry during venography has demonstrated considerable pressure gradients across the stenotic segments with elevated venous pressures proximal to the stenosis. Although it is not clear whether DVSS is the cause or consequence of refractory IIH, our results indicate that lowering the venous system pressure via stenting of the stenotic vein could be an effective approach in resolution of clinical signs and symptoms. In fact, decreasing the intraluminal pressure in the venous system can promote CSF absorption in venous arachnoid granulations, thus reducing ICP. Furthermore, the venous system has been shown to act as a Starling resistor and thus raised ICP does restrict venous outflow, especially at the level of cortical veins, and helps maintain the balance between blood inflow and CSF outflow. Although stenting of the venous sinus stenosis has been shown to resolve the pressure gradient, the effect on ICP remains inconclusive. Only few studies reported ICP changes following venous stenting. Future studies should consider ICP measurements before and after venous stenting as well as during follow-up of these individuals.

Potential major complications following dural venous sinus stenting include intracranial hemorrhage, venous thrombosis with secondary ischemic complications, as well as proce- 
Saber et al.: Stent Survival and Stent-Adjacent Stenosis Rates following Venous Sinus

\begin{tabular}{|c|c|c|c|c|c|c|c|c|c|}
\hline Study & Events & Total & & & & & $\begin{array}{l}\text { Proportion } \\
(95 \% \mathrm{Cl})\end{array}$ & $\begin{array}{l}\text { Weight } \\
\text { (fixed), \% }\end{array}$ & $\begin{array}{l}\text { Weight } \\
\text { (random), \% }\end{array}$ \\
\hline Higgins [4], 2003 & 0 & 12 & $\longmapsto$ & & & & $0.00(0.00,0.26)$ & 1.2 & 1.2 \\
\hline Owler [5], 2003 & 1 & 4 & 1 & & & & $0.25(0.01,0.81)$ & 1.9 & 1.9 \\
\hline Donnet [6], 2008 & 0 & 10 & $\begin{array}{ll}1 \\
1\end{array}$ & & & & $0.00(0.00,0.31)$ & 1.2 & 1.2 \\
\hline Ahmed [7], 2011 & 6 & 52 & 11 & & & & $0.12(0.04,0.23)$ & 13.3 & 13.3 \\
\hline Albuquerque [8], 2011 & 1 & 14 & $\longrightarrow \quad 1$ & & & & $0.07(0.00,0.34)$ & 2.3 & 2.3 \\
\hline Fields [9], 2011 & 0 & 15 & $\begin{array}{l}1 \\
1\end{array}$ & & & & $0.00(0.00,0.22)$ & 1.2 & 1.2 \\
\hline Kumpe [10], 2012 & 1 & 16 & 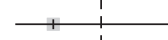 & & & & $0.06(0.00,0.30)$ & 2.3 & 2.3 \\
\hline Radvany [20], 2013 & 2 & 12 & t+ & & & & $0.17(0.02,0.48)$ & 4.2 & 4.2 \\
\hline Teleb [22], 2012 & 0 & 18 & $\longmapsto$ & & & & $0.00(0.00,0.19)$ & 1.2 & 1.2 \\
\hline Ducruet [11], 2014 & 5 & 23 & 1 & & & & $0.22(0.07,0.44)$ & 9.8 & 9.8 \\
\hline Goodwin [12], 2014 & 2 & 18 & 1 & & & & $0.11(0.01,0.35)$ & 4.5 & 4.5 \\
\hline Elder [13], 2015 & 1 & 4 & & & & & $0.25(0.01,0.81)$ & 1.9 & 1.9 \\
\hline Liu [14], 2017 & 2 & 10 & $1+$ & & & & $0.20(0.03,0.56)$ & 4.0 & 4.0 \\
\hline Smith [21], 2017 & 5 & 14 & $\frac{1}{1}$ & + & & & $0.36(0.13,0.65)$ & 8.1 & 8.1 \\
\hline Dinkin [15], 2017 & 1 & 13 & 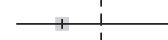 & & & & $0.08(0.00,0.36)$ & 2.3 & 2.3 \\
\hline Kumpe [29], 2017 & 7 & 39 & $\begin{array}{l}1 \\
1\end{array}$ & & & & $0.18(0.08,0.34)$ & 14.4 & 14.4 \\
\hline Lenck [16], 2016 & 1 & 21 & $\mp \quad 1$ & & & & $0.05(0.00,0.24)$ & 2.4 & 2.4 \\
\hline Aguilar-Pérez [17], 2017 & 7 & 48 & $\frac{i}{i}$ & & & & $0.15(0.06,0.28)$ & 15.0 & 15.0 \\
\hline Asif [18], 2017 & 2 & 41 & $\begin{array}{l}1 \\
+\quad 1\end{array}$ & & & & $0.05(0.01,0.17)$ & 4.8 & 4.8 \\
\hline Satti [19], 2017 & 2 & 11 & $\begin{array}{l}1 \\
1+1\end{array}$ & & & & $0.18(0.02,0.52)$ & 4.1 & 4.1 \\
\hline \multirow{4}{*}{$\begin{array}{l}\text { Fixed-effects model } \\
\text { Random-effects model } \\
\text { Heterogeneity: } R^{2}=0 \%, \tau^{2}\end{array}$} & & 395 & & & & & $0.14(0.11,0.18)$ & 100.0 & - \\
\hline & & & & & & & $0.14(0.11,0.18)$ & - & 100.0 \\
\hline & $=0, p$ & $=0.51$ & & & & & & & \\
\hline & & & 0.2 & 0.4 & 0.6 & 0.8 & & & \\
\hline
\end{tabular}

Fig. 2. Stent-adjacent stenosis rate.

dural complications. In our systematic review, these major complications were seen in less than $2 \%$ of procedures.

The novel results from our analysis are an estimation of stent survival and stent-adjacent stenosis in 24 studies. A major reason for stenting failure or the need for stent revision is stenosis proximal or distal to the stent (juxta-stent stenosis). As mentioned previously, the cause of such juxta stenosis could be related to elevated ICP or pressure gradients, continued extrinsic compression, floppy sinuses, or uncontrolled endothelialization as it seems to occur not immediately. One study noted sigmoid stent stenosis at 6 months after stenting for venous hypertension, and intravascular ultrasound revealed intimal proliferation that improved upon angioplasty. These findings also fit with the higher-pressure gradients as increased turbulence could result in greater shear stress in stents. Endothelial cells in veins compared to arteries are noted to be shorter and wider, compared to their long and narrow arterial counterparts, in addition normal levels of shear encountered by veins are typically a 10 th of the arterial side. Looser intercellular junctions in veins are also noted compared to arteries [28]. In-stent stenosis was seen in a small number of patients with DVSS which is similar to rates reported for venous sinus stenting in other patient populations. Venous sinuses are lowpressure systems and, therefore, are thought to be associated with a lower risk of in-stent stenosis and atherosclerosis compared to the arterial system. However, the low-pressure sinuses are more prone to compression when ICP is high. Some studies have suggested that longer stents or the use of more than 1 stent may reduce the risk of juxta-stent stenosis after venous stenting, especially in the setting of extrinsic compression or very high-pressure gradients [7]. A recent study by Asif et al. [18] reported similar stent survival rates of $87 \%$ at 
120 days. However, complications were slightly higher at $4.9 \%$ and efficacy for reduction of papilledema was lower (63\% reduction) than in our study. However, future studies will be needed to further characterize the patient population at an increased risk of juxta-stent stenosis, as well as optimal management approaches for affected individuals, which will likely include additional stent placement or shunting. The most common antithrombotic regimen included dual anti-platelet therapy (aspirin and clopidogrel) for 6 days before the procedure and for 6 months after the procedure, followed by aspirin lifelong.

\section{Limitations}

The number of treated patients is still small. Criteria for enrollment of eligible patients were not similar in all studies. Most included studies were case series or had a small number of participants. Publication bias is a major concern given the fact that series with less desirable surgical outcomes may be less likely to be reported and/or published. Additionally, most studies did not report CSF pressures after venous stenting or at follow-up visits.

\section{Conclusions}

In patients with refractory IIH and DVSS with an elevated pressure gradient across the site of stenosis, venous sinus stenting is associated with a significant reduction of venous pressure gradient, ICP, and improvement in clinical signs and symptoms of IIH. Stent survival rates are acceptable, and juxta-stent stenosis is the major reason for stent revisions. Future studies are needed to identify determinants of stent-adjacent stenosis and stent nonsurvival.

\section{Acknowledgement}

We thank the participants and staff of all the included studies.

\section{Disclosure Statement}

The authors have nothing to disclose.

\section{References}

1 Chiu AHY, Cheung AK, Wenderoth JD, De Villiers L, Rice H, Phatouros CC, et al: Long-term follow-up results following elective treatment of unruptured intracranial aneurysms with the pipeline embolization device. Am J Neuroradiol 2015;36:1728-1734.

2 Satti SR, Leishangthem L, Chaudry MI: Meta-analysis of CSF diversion procedures and dural venous sinus stenting in the setting of medically refractory idiopathic intracranial hypertension. Am J Neuroradiol 2015; 36:1899-1904.

3 Mollan SP, Ali F, Hassan-Smith G, Botfield H, Friedman DI, Sinclair AJ: Evolving evidence in adult idiopathic intracranial hypertension: pathophysiology and management. J Neurol Neurosurg Psychiatry 2016;87:982992.

4 Higgins JNP, Cousins C, Owler BK, Sarkies N, Pickard JD: Idiopathic intracranial hypertension: 12 cases treated by venous sinus stenting. J Neurol Neurosurg Psychiatry 2003;74:1662-1666.

5 Owler BK, Parker G, Halmagyi GM, Dunne VG, Grinnell V, McDowell D, et al: Pseudotumor cerebri syndrome: venous sinus obstruction and its treatment with stent placement. J Neurosurg 2003;98:1045-1055.

6 Donnet A, Metellus P, Levrier O, Mekkaoui C, Fuentes S, Dufour H, et al: Endovascular treatment of idiopathic intracranial hypertension: clinical and radiologic outcome of 10 consecutive patients. Neurology 2008;70: 641-647. 
7 Ahmed RM, Wilkinson M, Parker GD, Thurtell MJ, Macdonald J, McCluskey PJ, et al: Transverse sinus stenting for idiopathic intracranial hypertension: a review of 52 patients and of model predictions. Am J Neuroradiol 2011;32:1408-1414.

8 Albuquerque FC, Dashti SR, Hu YC, Newman CB, Teleb M, McDougall CG, et al: Intracranial venous sinus stenting for benign intracranial hypertension: clinical indications, technique, and preliminary results. World Neurosurg 2011;75:648-652.

9 Fields JD, Javedani PP, Falardeau J, Nesbit GM, Dogan A, Helseth EK, et al: Dural venous sinus angioplasty and stenting for the treatment of idiopathic intracranial hypertension. J Neurointerv Surg 2013;5:62-68.

10 Kumpe DA, Bennett JL, Seinfeld J, Pelak VS, Chawla A, Tierney M: Dural sinus stent placement for idiopathic intracranial hypertension. J Neurosurg 2012;116:538-548.

11 Ducruet AF, Crowley RW, McDougall CG, Albuquerque FC: Long-term patency of venous sinus stents for idiopathic intracranial hypertension. J Neurointerv Surg 2014;6:238-242.

12 Goodwin CR, Elder BD, Ward A, Orkoulas-Razis D, Kosztowski TA, Hoffberger J, et al: Risk factors for failed transverse sinus stenting in pseudotumor cerebri patients. Clin Neurol Neurosurg 2014;127:75-78.

13 Elder BD, Rory Goodwin C, Kosztowski TA, Radvany MG, Gailloud P, Moghekar A, et al: Venous sinus stenting is a valuable treatment for fulminant idiopathic intracranial hypertension. J Clin Neurosci 2015;22:685-689.

14 Liu KC, Starke RM, Durst CR, Wang TR, Ding D, Crowley RW, et al: Venous sinus stenting for reduction of intracranial pressure in IIH: a prospective pilot study. J Neurosurg 2017;127:1126-1133.

15 Dinkin MJ, Patsalides A: Venous sinus stenting in idiopathic intracranial hypertension. J Neuroophthalmol 2017;37:113-121.

16 Lenck S, Vallée F, Labeyrie M-A, Touitou V, Saint-Maurice J-P, Guillonnet A, et al: Stenting of the lateral sinus in idiopathic intracranial hypertension according to the type of stenosis. Neurosurgery 2016;80:1.

17 Aguilar-Pérez M, Martinez-Moreno R, Kurre W, Wendl C, Bäzner H, Ganslandt O, et al: Endovascular treatment of idiopathic intracranial hypertension: retrospective analysis of immediate and long-term results in 51 patients. Neuroradiology 2017;59:277-287.

18 Asif H, Craven CL, Siddiqui AH, Shah SN, Matloob SA, Thorne L, et al: Idiopathic intracranial hypertension: 120-day clinical, radiological, and manometric outcomes after stent insertion into the dural venous sinus. J Neurosurg 2017, Epub ahead of print.

19 Satti SR, Leishangthem L, Spiotta A, Chaudry MI: Dural venous sinus stenting for medically and surgically refractory idiopathic intracranial hypertension. Interv Neuroradiol 2017;23:186-193.

20 Radvany MG, Solomon D, Nijjar S, Subramanian PS, Miller NR, Rigamonti D, et al: Visual and neurological outcomes following endovascular stenting for pseudotumor cerebri associated with transverse sinus stenosis. J Neuroophthalmol 2013;33:117-122.

21 Smith KA, Peterson JC, Arnold PM, Camarata PJ, Whittaker TJ, Abraham MG: A case series of dural venous sinus stenting in idiopathic intracranial hypertension: association of outcomes with optical coherence tomography. Int J Neurosci 2017;127:145-153.

22 Teleb MS, Rekate H, Chung S, Albuquerque FC: Pseudotumor cerebri presenting with ataxia and hyper-reflexia in a non-obese woman treated with sinus stenting. J Neurointerv Surg 2012;4:e22.

23 Shazly TA, Jadhav AP, Aghaebrahim A, Ducruet AF, Jankowitz BT, Jovin TG, et al: Venous sinus stenting shortens the duration of medical therapy for increased intracranial pressure secondary to venous sinus stenosis. J Neurointerv Surg 2018;10:310-314.

24 Esfahani DR, Stevenson M, Moss HE, Amin-Hanjani S, Aletich V, Jain S, et al: Quantitative magnetic resonance venography is correlated with intravenous pressures before and after venous sinus stenting. Neurosurgery 2015;77:254-260.

25 Bussiere M, Falero R, Nicolle D, Proulx A, Patel V, Pelz D: Unilateral transverse sinus stenting of patients with idiopathic intracranial hypertension. Am J Neuroradiol 2010;31:645-650.

26 Silva J, Conti M, Aguiar G, Jory M, Monzillo P, Veiga J: Endovascular treatment for idiopathic intracranial hypertension improves clinical symptoms and signs. Arq Bras Neurocir 2017;36:01-06.

27 Durcan FJ, Corbett JJ, Wall M: The incidence of pseudotumor cerebri. Population studies in Iowa and Louisiana. Arch Neurol 1988;45:875-877.

28 dela Paz NG, D'Amore PA: Arterial versus venous endothelial cells. Cell Tissue Res 2009;335:5-16.

29 Kumpe DA, Seinfeld J, Huang X, Mei Q, Case DE, Roark CD, Subramanian PS, Lind KE, Pelak VS, Bennett JL: Dural sinus stenting for idiopathic intracranial hypertension: factors associated with hemodynamic failure and management with extended stenting. J Neurointerv Surg 2017;9:867-874. 